\title{
THE QUESTION OF GENRE
}

ON THE RIGHT of Rembrandt's anatomy-picture of 1632 (PI. 2) the physician Nicolaes Tulp, doctor of medicine (Leiden) and praelector anatomiae to the Amsterdam guild of surgeons, demonstrates a dissection of the forearm of a corpse. To the left of him we see seven surgeons of Amsterdam who are identified as such from the list of names on the paper held by one of them. Each name on the list is numbered, and a corresponding number is painted on the canvas by the head of each of the sitters, so enabling us to identify them. But although the authenticity of the names recorded in the list can be confirmed from other sources, ${ }^{1}$ the list itself is thought to be one of three important additions or alterations which, together with numerous minor alterations, make the painting as it now exists no longer the painting which Rembrandt painted.

The grounds for suspecting that the list was added later are, first, that it is superimposed on an anatomical figure which is painted in a Rembrandtian manner but which the list obscures ( $\mathrm{Pl}$. 16); and second, that the list includes as its penultimate item the name of the surgeon whose portrait is crammed in on the extreme left edge of the canvas, Jacob Colevelt (Pl. 2). Colevelt's portrait is painted in a different technique from the others, and this fact, together with its unfortunate position, suggests that it also is a later addition by another hand. ${ }^{2}$ The list, which records its presence, must have been added later still. The third significant alteration affects the surgeon at the peak of the pyramid, Frans van Loenen: X-ray and infra-red photographs show that he was originally portrayed wearing a broad black hat which, though an important part of the original design, was for some reason painted out, perhaps by Rembrandt himself, at a very late stage in the execution. ${ }^{3}$

In order to see the picture approximately as Rembrandt painted it, we must therefore remove the list of names, restore the anatomical figure, expel the portrait of Colevelt, and reconstruct the hat of van Loenen. Having made these restorations on a photograph (Pl. 1, frontispiece), we find that Rembrandt composed his six surgeons in two triangles, one inner and one outer. The three surgeons who form the inner triangle attend eagerly to various aspects of the demonstration, and therefore remain mentally within the picture. The surgeon at the apex of this triangle peers at the book at the feet of the corpse. The three who form the outer triangle (PI. 1) seem to look in various directions out of the picture. The hatted surgeon at the apex of this larger triangle looks straight out at the viewer. The original composition (PI. 1) appears more rational and more coherent than the picture in its present, altered state (PI. 2), which is spoiled by the addition of one figure, Jacob Colevelt, looking into the picture from a position outside even the outer triangle.

\footnotetext{
' Mauritshuis p. 99.

2 Ibid., pp. 83, 86-87, 102-103, 105.

${ }^{3}$ On the hat: Mauritshuis pp. 84-86, 105, and Heckscher n. 48.
} 


\section{The paradox of Rembrandt's 'Anatomy of Dr. Tulp'}

In the foregoing characterization of the sitters, we have included a commonplace of the literature on Rembrandt's painting: some of the sitters look out of the picture, while others remain mentally within it. Yet many of those who have accepted this view without question have proceeded to a larger interpretation with which it is not entirely compatible. Rembrandt's picture of 1632 is regarded as a revolutionary composition on the ground that it is a group-portrait which purports to be, in addition, a likeness of an "anatomy lesson": Dr. Tulp is speaking to teach, the surgeons are listening to learn. By contrast, the earlier pictures of this subject, by Aert Pietersz. (1603). Michiel and Pieter van Miereveld (1617), Thomas de Keyser (1619), and Nicolaes Eliasz. (1625) are regarded as group-portraits and nothing more (Pls. 3, 4, 5, 6). Here the praelectors who would, in a lesson, be speaking, have their mouths shut, and most of those who would be paying attention to them are looking away towards the spectator instead. In these earlier pictures the anatomy appears not as a momentary event but as an attribute which indicates the lifelong profession of the sitters. Whether the praelector is speaking or silent, whether the surgeons look at the dissection or unhistorically away from it, they are all immortalized by their painters as members or officers of a guild of surgeons. Rembrandt, according to this view, was the first painter to go beyond this ideal, in that he not only indicated the profession of the sitters, but also gave the impression of a historical event, an "anatomy lesson", taking place before the viewer. ${ }^{4}$ The question whether or not such an event ever occurred would not affect the vividness of the impression, nor the painter's achievement in creating it.

The incompatibility between this interpretation of Rembrandt's picture and the detailed description of his sitters' attitudes has usually been overlooked. It is certainly true to say of Rembrandt's inner three surgeons and the praelector that they are depicted as characters in a historical painting: they are all caught up in the same event, they are unaware of the viewer, their attitudes are rational and spontaneous, and they show a sense of the moment. But these qualities are not all found in the outer group of surgeons, who are considered to be looking out of the picture. Their attitudes (PI. 1) are as unhistorical as the attitudes of those surgeons in the front row of Aert Pietersz.'s composition of 1603 (PI. 3), who appear to turn $180^{\circ}$ away from the anatomy to show their faces to the viewer. In the pose of his outer three surgeons, Rembrandt, like Pietersz., seems to have yielded to the demand of traditional portraiture that he show the viewer sitters' faces which would historically have been hidden as they looked downwards or into depth. This concession has a more important effect in a group-portrait which is modelled on an anatomy than in one which is modelled on a banquet, muster, or committee. For in those three cases, the sitters can let their attention wander out of the picture without defeating the ostensible purpose of the setting. But in anatomy-pictures there is no historically legitimate object for the sitters' attention apart from the anatomy itself: if they look away from the anatomy, it

\footnotetext{
${ }^{4}$ Mauritshuis pp. 98, 102, reflect the general view, which O. Benesch, Rembrandt, Lausanne, Skira, 1957, pp. 43-44, states concisely thus: "While in previous Amsterdam group portraits there is always something stiff and constrained about the figures, Rembrandt succeeded in linking them together and breathing organic life and unity into them. They form not only a well-constructed, well-balanced, pyramidal composition in the spirit of Italian art, but also a psychologically unified group listening attentively to Professor [sic] Tulp's lecture".
} 


\section{The question of genre}

immediately loses its historicity with respect to them, and takes on automatically the nature of an attribute, as it must, according to our analysis, for Rembrandt's outer triangle of surgeons.

Hence, Rembrandt's design of 1632 (Pl. 1), far from breaking with previous traditions, adopts the same compromise as Thomas de Keyser's of 1619 (Pl. 5). In each picture, the sitters are divided by the same criterion: whether, owing to their position in the picture, their looking at the anatomy would or would not produce a marketable facial portrait. If it would, they look at the anatomy, which is therefore historical. If it would not, they look at the viewer, and accept the anatomy as an attribute. By this criterion, de Keyser (PI. 5) managed to have, out of six sitters, four historical and two attributive, while Rembrandt (PI. 1), out of seven sitters, had four historical and three attributive. On a simple count of heads, Rembrandt's design, paradoxically, is proportionately less historical, more attributive, more traditional, than de Keyser's.

Qualitatively, on the other hand, Rembrandt's "historical" surgeons (the inner three in Pl. 1) may seem more historical than de Keyser's equivalents (the back three in Pl. 5), but this also is disputable. Rembrandt's subjects are deeply absorbed by the lesson, while de Keyser's show only a shallow interest. But are the former necessarily more plausible historically? On the contrary: once this criterion of "historicity" or implied narrative has been allowed into our criticism, we are even free to remark that since the surgeons in both pictures are well into middle age, they must have heard plenty of anatomy lectures before, ${ }^{5}$ and so the detached attitudes of de Keyser's elders are no less realistic than the almost ingratiating zeal of Rembrandt's, as can be confirmed from PI. 7.

There is another reason for comparing Rembrandt's picture with de Keyser's. The anatomy in each picture has two incompatible functions, historical with respect to some of the, sitters, attributive with respect to the others. In order to soften the incongruity between these two functions, de Keyser, an experienced portraitist, has quietened the historical element: his surgeons who do look at the skeleton (PI. 5) do not pretend to be engrossed in anatomical study, so we are less inclined to complain that his other surgeons do not look at it at all. In this picture one scarcely notices any conflict of genres. The youthful Rembrandt, however, with his training as a historical painter, seems to have rushed into the trap. For by intensifying the historical atmosphere in one part only, he has sharpened the incongruity between the historical heart of his painting and its attributive periphery, so leaving the viewer in two minds as to the subject of the whole. For if in Pl. 1 the inner three surgeons are understood to be paying attention to the lecturer, by the same criterion the outer three ought to seem to be rudely ignoring him. But if it is the outer three who set the tone, the inner three seem to serve merely as attributes to them. The unease which many people feel on looking at Rembrandt's painting is a natural result of this unfortunate juxtaposition of two different conventions in one and the same picture. ${ }^{6}$

\footnotetext{
${ }^{5}$ On the anatomical knowledge gained by one of the surgeons present in Rembrandt's picture, $M$. Calkoen, see p. 55 below.

'Such unease is expressed by, among others, W. F. Bynum, 'Anatomy lecture on the brain', J. Hist. Med., 1968, 23: 196; T. Copplestone, Rembrandt, 4th ed., London, Hamlyn, 1974, p. 33; Christopher Wright, Rembrandt and his art, London, Hamlyn, 1975, p. 23.
} 


\section{The paradox of Rembrandt's 'Anatomy of Dr. Tulp'}

Hence, although Rembrandt's painting is usually judged superior to the earlier works, the criteria of judgment that are used ought to suggest the opposite conclusion: his Tulp picture, on these terms, is successful neither as a history-picture nor as an attributive group-portrait. This conclusion is the starting-point of our investigation, for it provokes us to wonder whether the fault may lie not with Rembrandt but in the traditional identification of the genre and subject of the picture. These suspicions are indeed confirmed by the following, more minute, examination of the painting.

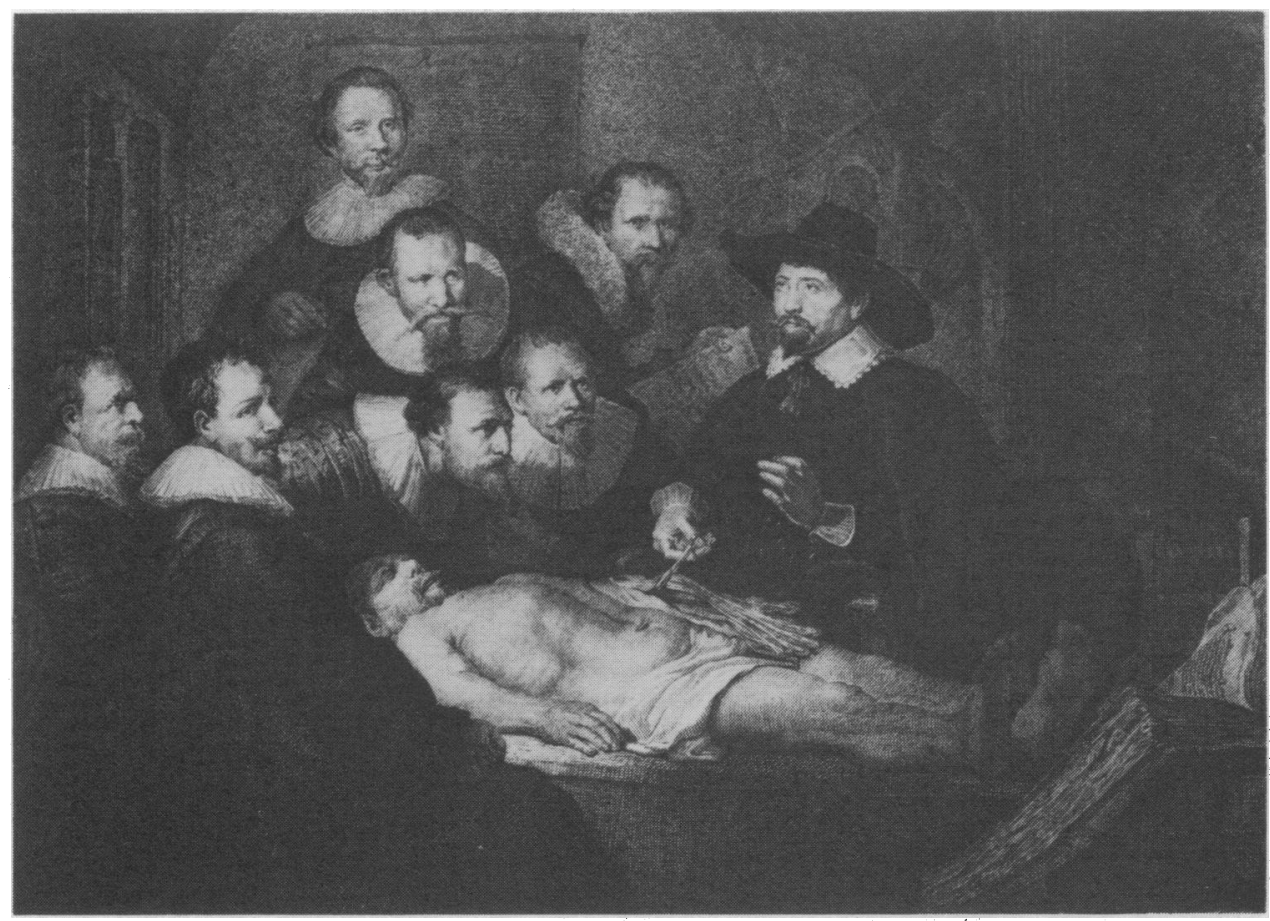

Figure 1. J. de Frey, 'The anatomy of Dr. Nicolaes Tulp' (so called), etching, 1798, after Rembrandt's painting (PI. 2). The structure on the right is the etcher's attempt to render the back of the chair on the seat of which the books are placed. 